\title{
Analisis Produktivitas Tenaga Kerja pada Bagian Produksi Menggunakan Metode Produktivitas Parsial di PT Prima Kemasindo
}

\author{
Habibah $^{1 *}$, Dene Herwanto ${ }^{2}$ \\ ${ }^{1,2}$ Program Studi Teknik Industri, Fakultas Teknik, Universitas Singaperbangsa Karawang, Karawang \\ *Koresponden email: habibah47992@ gmail.com
}

Diterima: 28 Desember 2021

Disetujui: 20 Januari 2022

\begin{abstract}
PT Prima Kemasindo is a company that focuses on producing a variety of quality drinks, one of which is nata de coco or coconut juice. The machine used in producing this coconut juice drink is a filling machine. The amount of nata de coco production can be said to be unstable, this can be seen in the production results that there are decreases and increases every month. This study aims to analyze the level of labor productivity and what factors affect labor productivity at PT Prima Kemasindo. This study uses the partial productivity method to determine the level of labor productivity each month. The production output produced in January was 295604, in February it was 224714 and in March it was 279744. Labor productivity decreased in January by $95 \%$ (less than $100 \%$ ), while February and March increased by $111 \%$ and $103 \%$.
\end{abstract}

Keywords: PT Prima Kemasindo, labor productivity, partial productivity, production, profitability

\begin{abstract}
Abstrak
PT Prima Kemasindo merupakan salah satu perusahaan yang memfokuskan diri dalam memproduksi berbagai minuman berkualitas salah satunya yaitu minuman nata de coco atau sari kelapa. Mesin yang digunakan dalam memproduksi minuman sari kelapa ini yaitu mesin filling. Jumlah produksi nata de coco dapat dikatakan tidak stabil, hal ini terlihat pada hasil produksi terdapat penurunan dan peningkatan setiap bulannya. Penelitian ini bertujuan untuk menganalisis tingkat produktivitas tenaga kerja dan faktor apa saja yang mempengaruhi produktivitas tenaga kerja yang ada di PT Prima Kemasindo. Penelitian ini menggunakan metode produktivitas parsial untuk mengetahui tingkat produktivitas tenaga kerja setiap bulannya. Output produksi yang dihasilkan pada bulan Januari yaitu sebesar 295604, pada bulan Februari yaitu 224714 dan pada bulan Maret yaitu sebesar 279744. Produktivitas tenaga kerjanya mengalami penurunan pada bulan Januari yaitu 95\% (kurang dari 100\%), sedangkan bulan Februari dan Maret mengalami kenaikan sebesar $111 \%$ dan $103 \%$.

Kata Kunci: PT Prima Kemasindo, produktivitas tenaga kerja, produktivitas parsial, produksi, profitabilitas
\end{abstract}

\section{Pendahuluan}

Seiring dengan perkembangan zaman yang pesat, dan kondisi persaingan yang semakin ketat perusahaan bersaing untuk mempertahankan usahanya, oleh karena itu perusahaan harus mengetahui kemampuan tenaga kerjanya untuk meningkatkan profit dengan upaya pengukuran produktivitas, Menurut ref. [1] hasil pengukuran akan digunakan sebagai evaluasi untuk proses perusahaan sehari-hari, sehingga kegiatan perusahaan lebih efisien dan efektif. Proses pengukuran produktivitas selama periode waktu disebut siklus produktivitas yang mencakup pengukuran, evaluasi, perencanaan dan peningkatan. Peningkatan produktivitas dapat dilakukan oleh perusahaan melalui dua sisi yaitu: individual dan organisasi. meningkatkan produktivitas individu antara lain dengan meningkatkan kemampuan karyawan dan produktivitas karyawan terkait sinergi kerja antara departemen internal perusahaan, dukungan teknologi di dalam perusahaan dan berbagai fasilitas lain yang dapat meningkatkan efisiensi dan efektivitas kerja [2].

Perusahaan harus menjaga produktivitas guna menjaga stabilitas perusahaan agar efektif dan efisien dalam menjalankan kegiatan produksi, misalnya pada tenaga kerja, bahan baku, penjualan, organisasi dan sumber daya keuangan, utama atau modal [3][4]. Peningkatan produktivitas perusahaan dapat dicapai apabila perusahaan memiliki kemampuan dalam mengelola sumber daya manusia dengan baik. memang sumber daya manusia (SDM) merupakan faktor manusia yang memegang peranan utama dalam setiap kegiatan operasional suatu perusahaan. Semakin baik kapasitas sumber daya manusia yang dimiliki maka 
akan semakin baik hasil dan sebaliknya [5]. Produktivitas karyawan di perusahaan juga tergantung pada kerja sama yang efektif antara individu dan kelompok. Menurut ref. [6] produktivitas menjadi perbandingan antara totalitas pengeluaran dalam ketika eksklusif dibagi masukan selama periode tersebut.

Permasalahan yang selama ini dihadapi oleh PT Prima Kemasindo adalah banyaknya karyawan yang kurang disiplin dalam bekerja dan kurangnya pengawasan sehingga banyak karyawan yang mengobrol sesama karyawan saat mereka sedang melakukan pekerjaan serta panasnya suhu lingkungan yang menyebabkan karyawan mudah lelah. Hal-hal tersebut dapat menyebabkan produktivitas PT Prima Kemasindo, khususnya produktivitas tenaga kerja, menjadi menurun. Analisis dan evaluasi terhadap tingkat produktivitas, khususnya produktivitas tenaga kerja, di PT Prima Kemasindo perlu dilakukan untuk mengetahui penyebab terjadinya penurunan produktivitas sehingga dapat diperbaiki, dan hal-hal yang sudah baik dapat dipertahankan maupun ditingkatkan lagi. Metode yang dapat digunakan untuk mengukur produktivitas tenaga kerja di PT Prima Kemasindo ini adalah metode pengukuran produktivitas parsial, dengan perbaikan menggunakan diagram sebab akibat (fishbone).

Produktivitas adalah suatu pendekatan interdisipliner untuk menentukan tujuan yang efektif, pembuatan, aplikasi penggunaan cara yang produktivitas untuk menggunakan sumber-sumber secara efisien dan tetap menjaga adanya kualitas yang tinggi [7]. Produktivitas merupakan perbandingan efektivitas menghasilkan keluaran (output) dengan efisiensi penggunaan sumber-sumber masukan (input) [8] Rasio produktivitas merupakan nilai yang diukur selama proyek konstruksi, dapat dipisahkan sebagai porto energi tenaga kerja, material uang, metode $\&$ alat. Sukses atau tidaknya proyek konstruksi tergantung dalam efektivitas pengelolaan sumber daya [9]. Pengertian produktivitas dikemukakan orang dengan menunjukkan kepada rasio output terhadap input [10]. Menurut ref. [11], produktivitas tenaga kerja dapat dipengaruhi oleh beberapa faktor seperti umur, tingkat pendidikan formal, pengalaman kerja, upah dan curahan tenaga kerja. Menurut [11] faktor-faktor yang mempengaruhi produktivitas tenaga kerja yang diukur dengan pendekatan sistem antara lain (1) berkaitan dengan kualitas kapasitas fisik pekerja (2) fasilitas penunjang (3) fasilitas-fasilitas unggulan. Peningkatan produktivitas tenaga kerja di industri dipengaruhi oleh faktor bisnis (upah, teknologi, dll) serta tenaga kerja itu sendiri (usia, Pendidikan, pengalaman kerja dan jenis kelamin).

Menurut Sumanth dalam referensi. [12] produktivitas dibagi menjadi 3 kategori yaitu:

(1) Produktivitas total

Merupakan rasio antara total output dengan semua total input. Produktivitas total dirumuskan sebagai berikut:

(2) Produktivitas parsial

$$
\text { Produktivitas total }=\frac{\text { output } \text { Total }}{\text { input } \text { Total }}
$$

Merupakan rasio keluaran terhadap salah satu jenis masukan. Hasil pengukurannya akan lebih mudah digunakan sebagai masukan pada usaha-usaha perbaikan produktivitas dibandingkan dengan hasil pengukuran yang diperoleh dari produktivitas dibandingkan dengan hasil pengukuran yang diperoleh dari produktivitas total. Produktivitas parsial dirumuskan:

$$
\text { Pengukuran produktivitas parsial }=\frac{\text { output Total }}{\text { salah satu jenis input }}
$$

(3) Produktivitas total faktor

Merupakan rasio keluaran bersih terhadap jumlah masukan faktor tenaga kerja dan faktor kapital.

Produktivitas total faktor dirumuskan sebagai berikut:

\section{Metode Penelitian Objek penelitian}

$$
\text { Pengukuran produktivitas parsial }=\frac{\text { output bersih }}{\text { input }(\text { tenaga kerja }+ \text { modal })}
$$

Objek penelitian adalah sasaran ilmiah untuk mendapatkan data dengan tujuan dan kegunaan tertentu tentang sesuatu hal objektif, valid dan reliable tentang suatu hal (variabel tertentu) [13]. Penelitian ini menganalisis pengukuran produktivitas tenaga kerja, mengevaluasi, dan merencanakan serta perbaikan produktivitas. Objek penelitian ini adalah tenaga kerja bagian produksi PT Prima Kemasindo.

\section{Data dan pengumpulan data}

Data yang digunakan dalam penelitian ini adalah data primer dan data sekunder. Jenis penelitian yang digunakan dalam penelitian ini adalah penelitian deskriptif dengan pendekatan kuantitatif. Dalam penelitian ini menggunakan teknik pengumpulan data observasi untuk mengamati hasil produksi dan 
$\overline{\text { jumlah karyawan yang bekerja pada setiap harinya. Penelitian ini juga menggunakan teknik pengumpulan }}$ data dengan cara mewawancarai pihak-pihak perusahaan terutama pada bagian produksi.

\section{Teknik pengolahan data}

Teknik pembahasan yang digunakan dalam penelitian ini adalah teknik pembahasan deskriptif dengan pendekatan kualitatif dengan cara menggunakan teknik analisis produktivitas tenaga kerja. Data yang digunakan dalam 3 bulan dari bulan Januari-Maret 2021, yaitu (1) data hasil output produksi, dan (2) data jumlah karyawan yang bekerja. Analisis dalam pengolahan data dalam penelitian ini yaitu mengukur produktivitas tenaga kerja, mengevaluasi hasil produktivitas, merencanakan serta melakukan perbaikan pada produktivitas tenaga kerja.

\section{Teknik analisis data}

Teknik analisis data ini digunakan untuk mengambil kesimpulan dari data-data yang sudah diolah, maka dari itu teknik analisis data yang digunakan dalam penelitian ini adalah kuantitatif deskriptif yaitu analisis data dengan cara mendeskripsikan atau menggambarkan data yang telah terkumpul sebagaimana adanya tanpa bermaksud membuat kesimpulan yang berlaku untuk umum [13][14]. Dalam penelitian ini tujuan dari analisis kuantitatif deskriptif adalah untuk mendeskripsikan data mengenai tingkat produktivitas tenaga kerja pada bulan Januari-Maret 2021.

\section{Tahapan penelitian}

Langkah-langkah pada penelitian ini digambarkan menggunakan diagram alir (Flow Chart) seperti pada Gambar 1.

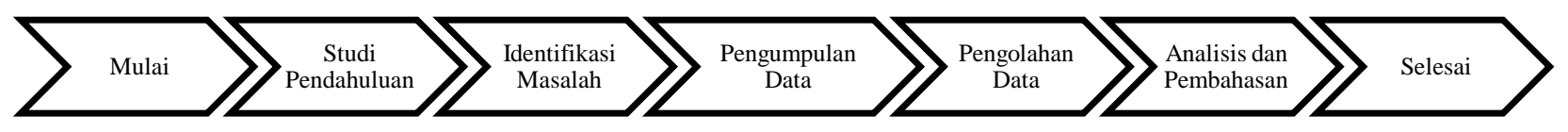

Gambar 1. Langkah-langkah penelitian

Sumber: Gunawan dkk. [15]

a. Mulai, pada tahapan ini dimulai pada bulan Maret 2021.

b. Studi pendahuluan yaitu studi literatur dan studi lapangan.

Studi literatur adalah studi untuk mencari referensi yang berkaitan dengan penelitian berupa buku, artikel jurnal, dan lain-lain. Sedangkan studi lapangan adalah melakukan observasi langsung ke lapangan untuk mengetahui keadaan sebenarnya.

c. Identifikasi masalah, yaitu mengidentifikasikan dan merumuskan permasalahan yang terjadi pada objek penelitian, permasalahan pada penelitian ini adalah terjadi penurunan produktivitas tenaga kerja.

d. Metodologi penelitian adalah alur atau langkah penelitian dimulai dari studi pendahuluan hingga analisis data.

e. Pengumpulan data. Data yang digunakan dalam penelitian ini adalah data primer dan data sekunder. Jenis penelitian yang digunakan dalam penelitian ini adalah penelitian deskriptif dengan pendekatan kuantitatif.

Dalam penelitian ini menggunakan teknik pengumpulan data observasi untuk mengamati hasil produksi dan jumlah karyawan yang bekerja pada setiap harinya. Penelitian ini juga menggunakan teknik pengumpulan data dengan cara mewawancarai pihak-pihak perusahaan terutama pada bagian produksi.

f. Pengolahan data, pada tahap ini dilakukan dengan menggunakan metode produktivitas parsial. Data yang digunakan adalah data output dan data jumlah karyawan yang bekerja.

g. Analisis dan pembahasan, digunakan untuk mengambil kesimpulan dari data-data yang sudah diolah, maka dari itu teknik analisis data yang digunakan dalam penelitian ini adalah kuantitatif deskriptif yaitu analisis data dengan cara mendeskripsikan atau menggambarkan data yang telah terkumpul sebagaimana adanya tanpa bermaksud membuat kesimpulan yang berlaku untuk umum. Diagram fishbone digunakan untuk mengetahui penyebab penurunan produktivitas tenaga kerja.

\section{Hasil dan Pembahasan}

Data penelitian ini merupakan data PT Prima Kemasindo selama 3 bulan yaitu pada bulan JanuariMaret 2021. Tabel 1 menunjukkan data output hasil produksi selama bulan Januari-Maret 2021. Jumlah produksi nata de coco dapat dikatakan tidak stabil atau tetap. Hal ini terlihat pada hasil produksi di atas, terdapat penurunan dan peningkatan setiap bulannya. Namun hal ini dikarenakan jumlah permintaan yang berbeda setiap bulannya, sehingga terjadi perubahan pada setiap bulannya. Menurut hasil wawancara dengan pihak manajemen, jumlah produksi yang mengalami perubahan setiap bulannya juga disebabkan 
karena hari libur atau day-off yang berbeda-beda. Waktu operasional PT Prima Kemasindo berlangsung $6 \times 24$ jam dalam seminggu.

Tabel 1. Data output hasil produksi bulan Januari 2021

\begin{tabular}{|c|c|c|c|c|c|c|c|c|}
\hline \multicolumn{6}{|c|}{ Total Karton } & \multicolumn{2}{|c|}{ ALL } & \multirow{3}{*}{ Total } \\
\hline \multicolumn{2}{|c|}{ I } & \multicolumn{2}{|c|}{ II } & \multicolumn{2}{|c|}{ III } & \multirow{2}{*}{ ACS 1} & \multirow{2}{*}{ ACS 2} & \\
\hline ACS 1 & ACS 2 & ACS 1 & ACS 2 & ACS 1 & ACS 2 & & & \\
\hline 11,948 & 15,563 & 9,060 & 52,290 & 30,861 & 45,730 & 51,869 & 113,583 & 165,452 \\
\hline 13,041 & - & 4,954 & 18,778 & 28,100 & - & 46,095 & 18,778 & 64,873 \\
\hline- & - & 4,875 & - & 12,772 & - & 17,647 & - & 17,647 \\
\hline- & - & 4,854 & - & - & 1,131 & 4,854 & 1,131 & 5,985 \\
\hline- & - & 4,508 & - & 4,733 & - & 9,241 & - & 9,41 \\
\hline- & - & - & - & - & - & - & - & - \\
\hline- & 350 & - & - & 4,588 & - & 4,588 & 350 & 4,938 \\
\hline- & - & - & - & - & - & - & - & - \\
\hline- & - & - & - & - & - & - & - & - \\
\hline 24,989 & 15,913 & 28,251 & 71,068 & 81,054 & 46,861 & 134,842 & 133,842 & 295,604 \\
\hline
\end{tabular}

Sumber: PT Prima Kemasindo (2021)

Tabel 2. Data output hasil produksi bulan Februari 2021

\begin{tabular}{|c|c|c|c|c|c|c|c|c|}
\hline \multicolumn{6}{|c|}{ Total Karton } & \multicolumn{2}{|c|}{ ALL } & \multirow{3}{*}{ Total } \\
\hline \multicolumn{2}{|c|}{$\mathrm{I}$} & \multicolumn{2}{|c|}{ II } & \multicolumn{2}{|c|}{ III } & \multirow{2}{*}{ ACS 1} & \multirow{2}{*}{ ACS 2} & \\
\hline ACS 1 & ACS 2 & ACS 1 & ACS 2 & ACS 1 & ACS 2 & & & \\
\hline 4,910 & 4,118 & 33,548 & 32,696 & 28,270 & 27,643 & 66,728 & 64,457 & 131,185 \\
\hline- & - & 10,012 & 4,309 & 5,111 & - & 15,123 & 4,309 & 19,432 \\
\hline- & - & 13,879 & 4,395 & 9,941 & - & 23,820 & 4,395 & 28,215 \\
\hline- & - & - & 9,800 & - & 3,004 & - & 12,804 & 12,804 \\
\hline- & - & - & 4,407 & - & 4,038 & - & 8,445 & 8,445 \\
\hline- & - & - & 4,649 & - & 8,800 & - & 13,449 & 13,449 \\
\hline- & - & - & 6,473 & 4,711 & - & - & 6,473 & 6,473 \\
\hline- & - & - & - & - & - & 4,711 & - & 4,711 \\
\hline - & - & - & - & - & - & - & - & - \\
\hline 4,910 & 4,118 & 57439 & 66729 & 48,033 & 43,485 & 110382 & 114332 & 224714 \\
\hline
\end{tabular}

Tabel 3. Data output hasil produksi bulan Maret 2021

\begin{tabular}{|c|c|c|c|c|c|c|c|c|}
\hline \multicolumn{6}{|c|}{ Total Karton } & \multicolumn{2}{|c|}{ ALL } & \multirow{3}{*}{ Total } \\
\hline \multicolumn{2}{|c|}{ I } & \multicolumn{2}{|c|}{ II } & \multicolumn{2}{|c|}{ III } & \multirow{2}{*}{ ACS 1} & \multirow{2}{*}{ ACS 2} & \\
\hline ACS 1 & ACS 2 & ACS 1 & ACS 2 & ACS 1 & ACS 2 & & & \\
\hline- & - & 32,292 & 31,949 & 44,367 & 33,280 & 76,659 & 65,229 & 141,888 \\
\hline- & - & 10,001 & - & 19,713 & 4,057 & 29,714 & 4,057 & 33,771 \\
\hline- & - & 25,372 & - & 4,539 & 1,284 & 29,911 & 1,268 & 31,179 \\
\hline- & - & 4,755 & 3,543 & - & 5,408 & 4,755 & 8,951 & 13,706 \\
\hline- & - & - & 5,000 & 421 & 8,225 & 421 & 13,225 & 13,646 \\
\hline- & - & - & 4,535 & - & 4,177 & - & 8,712 & 8,712 \\
\hline- & - & - & 9,052 & - & 8,149 & - & 17,201 & 17,201 \\
\hline- & - & 604 & - & 14,711 & - & 15,315 & - & 15,315 \\
\hline- & - & - & - & 4,310 & - & 4,310 & - & 4,310 \\
\hline- & - & 73024 & 54,079 & 88061 & 64580 & 161085 & 118643 & 279728 \\
\hline
\end{tabular}

Sumber: PT Prima Kemasindo (2021)

Faktor lain yang mempengaruhi perubahan fluktuatif hasil produksi adalah tenaga kerja itu sendiri, yaitu karyawan yang kurang disiplin dalam bekerja serta karyawan yang kurang kapasitas dalam menjalankan proses produksi terutama karyawan baru dan kurangnya pelatihan serta wawasan karyawan. Tenaga kerja keseluruhan yang terdapat di PT Prima Kemasindo berjumlah 2709 orang, dan 255 orang khusus office staff sedangkan 2.458 orang berhubungan dengan bagian produksi. Bagian office staff merupakan para karyawan yang mengerjakan urusan administrative dan lini proses produksi adalah karyawan yang bekerja dalam membuat dan mengolah produk dari mulai bahan baku (raw material) hingga bahan jadi (finish goods). 
Tabel 4. Jumlah karyawan pada bulan Januari-Maret 2021

\begin{tabular}{ccc}
\hline \multirow{2}{*}{ Bulan } & Periode & $\begin{array}{c}\text { Total jumlah karyawan yang masuk selama } \\
\text { 1 bulan }\end{array}$ \\
\hline Januari & 1 sd 31 Jan & 1037 \\
Februari & 1 sd 28 Feb & 672 \\
Maret & 1 sd 30 Mar & 1000 \\
\hline Total & & 2709 \\
\hline & Sumber: PT Prima Kemasindo (2021)
\end{tabular}

\section{Pengukuran terhadap produktivitas tenaga kerja}

Hasil pengukuran produktivitas tenaga kerja pada Bagian Produksi PT Prima Kemasindo periode Januari-Maret 2021 ditunjukkan pada Tabel 3.

Tabel 5. Pengukuran produktivitas tenaga kerja

\begin{tabular}{|c|c|c|c|c|c|c|c|}
\hline Bulan & Periode & $\begin{array}{c}\text { Total } \\
\text { karyawan } \\
\text { yang masuk } \\
\text { selama } 1 \\
\text { bulan }\end{array}$ & $\begin{array}{c}\text { Hasil } \\
\text { produksi per } \\
\text { bulan } \\
\text { (karton) }\end{array}$ & $\begin{array}{l}\text { Produktivitas } \\
\text { (karton) }\end{array}$ & $\begin{array}{l}\text { Standar } \\
\text { (karton) }\end{array}$ & $\%$ & Keterangan \\
\hline Januari & 1 - 31 Jan & 1037 & 295,604 & 285 & 300 & $95 \%$ & $\begin{array}{c}\text { Kurang } \\
\text { produktif }\end{array}$ \\
\hline Februari & $1-28 \mathrm{Feb}$ & 672 & 224,714 & 334 & 300 & $111 \%$ & Produktif \\
\hline Maret & 1 - 30 Mar & 1000 & 310,403 & 310 & 300 & $103 \%$ & Produktif \\
\hline Total & & 2709 & 830,721 & 307 & 300 & $309 \%$ & Produktif \\
\hline
\end{tabular}

Sumber: PT Prima Kemasindo (2021)

Perhitungan produktivitas tenaga kerja secara parsial dilakukan dengan rumus:

$$
\mathrm{PTK}=\frac{\text { hasil produksi }}{\text { jumlah karyawan }}
$$

Pada Tabel 3 dijelaskan hasil produktivitas tenaga kerja pada bulan Januari-Maret 2021, dengan perhitungan sebagai berikut:

(1) Perhitungan produktivitas tenaga kerja pada bulan Januari

$$
\begin{aligned}
\text { PTK } & =\frac{\text { hasil produksi }}{\text { jumlah karyawan }} \\
\text { PTK } & =\frac{695,604}{1037} \\
& =285 \\
\% & =\frac{285}{300} \times 100 \% \\
& =95 \% \text { (kurang produktif) }
\end{aligned}
$$

(2) Perhitungan produktivitas tenaga kerja pada bulan Februari

$$
\begin{aligned}
\text { PTK } & =\frac{\text { hasil produksi }}{\text { jumlah karyawan }} \\
\text { PTK } & =\frac{224,714}{672} \\
& =334 \\
\% & =\frac{334}{300} \times 100 \% \\
& =111 \% \text { (produktif) }
\end{aligned}
$$

(3) Perhitungan produktivitas tenaga kerja pada bulan Maret

$$
\begin{aligned}
\text { PTK } & =\frac{\text { Hasil produksi }}{\text { jumlah karyawan }} \\
\text { PTK } & =\frac{310,403}{1000} \\
& =310 \\
\% & =\frac{310}{300} \times 100 \%
\end{aligned}
$$


Nilai produktivitas dikatakan baik atau jika ingin ditingkatkan hasil pembagiannya harus naik atau lebih dari $100 \%$. Sebaliknya jika hasil pembagian turun atau kurang dari $100 \%$ maka dapat dikatakan produktivitas menurun. Dari hasil perhitungan yang dilakukan, nilai produktivitas tenaga kerja terhadap hasil produksi selama 3 bulan di PT Prima Kemasindo dikatakan sudah produktif atau baik apabila hasilnya lebih dari $100 \%$. Dengan nilai total produktivitas selama 3 bulan adalah $309 \%$ dan nilai rata-rata produktivitas adalah 103\% maka produktivitas dikatakan sudah baik. Dari hasil pengolahan data di atas maka dapat dianalisis penyebab turunnya produktivitas tenaga kerja pada PT Prima Kemasindo dengan menggunakan diagram sebab-akibat (fishbone) untuk menemukan akar penyebab masalahnya.

\section{Analisis penyebab naik-turunnya tingkat produktivitas}

Analisis penyebab naik-turunnya tingkat produktivitas tenaga kerja pada Bagian Produksi PT Prima Kemasindo ditunjukkan pada Gambar 2.

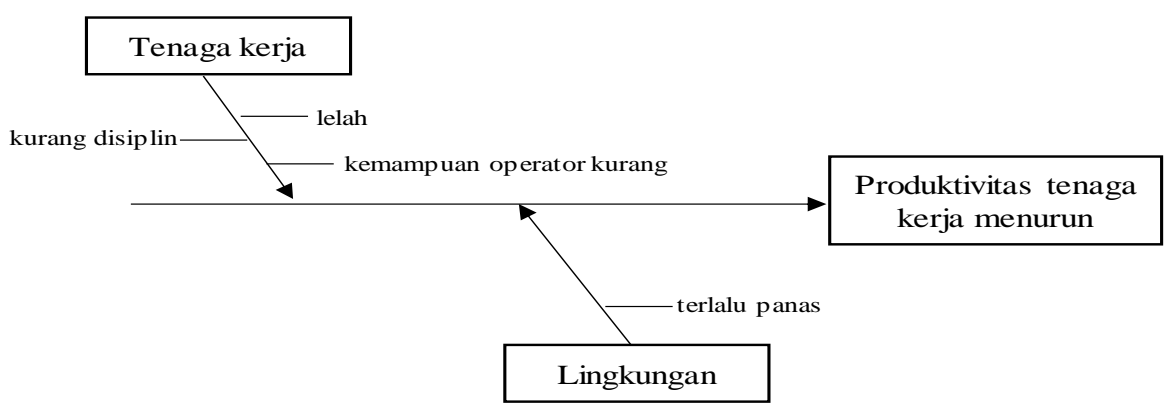

Gambar 2. Diagram fishbone

Sumber: PT Prima Kemasindo (2021)

(1) Tenaga kerja

Kurangnya pengawasan dalam mengawasi karyawannya sehingga mengakibatkan banyak karyawan yang kurang disiplin dalam bekerja dan masih banyak karyawan yang mengobrol sesama karyawan, dan kurangnya kemampuan operator dalam menjalan mesin, serta kurangnya diklat atau pelatihan terhadap karyawan khususnya karyawan baru.

(2) Lingkungan

Lingkungan yang terlalu panas mengakibatkan karyawan menjadi gampang lelah dan kurang fokus dalam menjalankan proses produksi dan mengakibatkan turunnya produktivitas.

\section{Perbaikan produktivitas}

Berdasarkan analisis terhadap penurunan produktivitas perusahaan maka dilakukan perencanaan yang dapat dijadikan dasar bagi perusahaan dalam melakukan perbaikan ataupun peningkatan produktivitas perusahaan.

(1) Perbaikan terhadap tenaga kerja; peningkatan produktivitas tenaga kerja yang dapat dilakukan adalah dengan cara melakukan adanya diklat atau pelatihan terhadap karyawan terutama karyawan baru, sehingga karyawan mengetahui celah dari mesin dan dapat memproduksi secara cepat dan tepat, dilakukannya pengawasan terhadap karyawan agar karyawan disiplin dalam bekerja dan tidak banyak yang mengobrol sesama karyawan saat bekerja.

(2) Dilakukannya perbaikan tempat kerja dengan diadakannya celah udara masuk ataupun diadakan blower atau kipas angin agar karyawan tidak merasa kepanasan saat melakukan proses produksi dan tidak cepat mengalami kelelahan.

\section{Kesimpulan}

Tingkat produktivitas tenaga kerja Bagian Produksi PT Prima Kemasindo pada bulan Januari-Maret 2021 dikatakan masih belum stabil atau tetap karena tingkat produktivitas pada bulan Januari belum produktif atau belum mencapai target produktivitas tenaga kerja (PTK) yaitu sebesar 95\%, sedangkan target PTK-nya yaitu sebesar 100\% atau satu. Sedangkan pada bulan Februari dan Maret sudah produktif karena telah mencapai target PTK yaitu sebesar $111 \%$ \& $103 \%$. 
Faktor-faktor yang mempengaruhi penurunan produktivitas yaitu tenaga kerja yang kurang disiplin dan sering merasa lelah, dan kemampuan operator yang kurang serta faktor lingkungan. Upaya perbaikan yang dapat dilakukan untuk meningkatkan produktivitas tenaga kerja adalah mengadakan diklat atau pelatihan terhadap semua karyawan terutama karyawan baru serta melakukan pengawasan terhadap semua karyawan. Selain itu juga dengan memperbaiki kondisi lingkungan agar tidak terlalu panas melalui penyediaan celah udara atau kipas angin atau blower.

\section{Referensi}

[1] R. N. Anthony and V. Govindarajan, Management Control System: Sistem Pengendalian Manajemen. Jakarta: Salemba Empat, 2014.

[2] O. A. Famade, J. O. Egbebi, and F. O. Akinkuowo, "An Assessment of Various Strategies in Enhancing Workers Productive Capacity in Nigeria's Tertiary Institutions," African Educ. Res. J., vol. 4, no. 3, pp. 91-95, 2016.

[3] R. Prabowo, "Pengendalian Persediaan Bahan Baku Oli Untuk Mesin Diesel Tipe G4J-801, G5J-801 dan G7J-801 di PT. Hansan Asembling - Malang," PROZIMA (Productivity, Optim. Manuf. Syst. Eng., vol. 1, no. 1, pp. 33-43, 2017, doi: 10.21070/prozima.v1i1.704.

[4] K. W. Suryanto, Tingkat Produktivitas Total dan Parsial PT. United Tractors dengan Menggunakan Model David J. Sumanth dan Habberstad (Pospac) yang Disesuaikan. Bandung: Program Magister Manajemen ITB, 2014.

[5] I. G. N. Budiartha, I. W. Bagia, and I. W. Suwendra, "Pengaruh Pelatihan dan Motivasi Kerja Terhadap Produktivitas Kerja Karyawan,” E-Journal Bisma, vol. 3, no. 09, pp. 1-10, 2015.

[6] I. M. A. Prabawa and I. W. G. Supartha, "Meningkatkan Produktivitas Karyawan Melalui Pemberdayaan, Kerjasama Tim dan Pelatihan di Perusahaan Jasa," e-Jurnal Manaj. Unud, vol. 7, no. 1, pp. 497-524, 2018.

[7] M. Sinungan, Produktivitas: Apa dan Bagaimana?, 2nd ed. Jakarta: Bumi Aksara, 2012.

[8] I. K. Ardana, N. W. Mujiati, and I. W. M. Utama, Manajemen Sumber Daya Manusia. Yogyakarta: Graha Ilmu, 2014.

[9] A. Bakar, O. Suprianto, and Y. Yuniati, "Usulan Peningkatan Produktivitas Berdasarkan Metode Mundel Dan Apc di Pt. Raffsya Media," J. Ind. Eng. Manag., vol. 2, no. 2, pp. 1-13, 2017, doi: 10.33536/jiem.v2i2.147.

[10] F. C. Gomes, Manajemen Sumber Daya Manusia. Yogyakarta: Andi Offset, 2013.

[11] Annisa Wanda Utami, A. Firman, and L. Herlina, "Analisis Produktivitas Tenaga Kerja pada Usaha Domba," e-Journals Students, vol. 4, no. 3, 2015, doi: 10.1145/3132847.3132886.

[12] Mulyadi, Akuntansi Manajemen: Konsep, Manfaat dan Rekayasa. Jakarta: Salemba Empat, 2011.

[13] Sugiyono, Metode Penelitian Kuantitatif, Kualitatif dan R\&B. Bandung: Alfabeta, 2012.

[14] Ardika Sulaeman, "Pengaruh Upah dan Pengalaman Kerja terhadap Produktivitas Karyawan Kerajinan Ukiran Kabupaten Subang," Trikonomika, vol. 13, no. 1, pp. 91-100, 2014.

[15] A. Gunawan, Kusnadi, and Hamdani, "Analisis Produktivitas Tenaga Kerja dengan Metode Marvin E. Mundel pada CV. Mulia Tata Sejahtera," Serambi Eng., vol. IV, pp. 1-9, 2021. 